\title{
Comparison of Two Mechanistic Microbial Growth Models to Estimate Shelf Life of Perishable Food Package under Dynamic Temperature Conditions
}

\author{
Dong Sun Lee \\ Department of Food Science and Biotechnology, Kyungnam University, 7 Kyungnamdaehak-ro, Masanhappo-gu, \\ Changwon 631-701, Republic of Korea
}

Correspondence should be addressed to Dong Sun Lee; dongsun@kyungnam.ac.kr

Received 14 July 2014; Accepted 17 September 2014; Published 1 October 2014

Academic Editor: Kit Keith L. Yam

Copyright (C) 2014 Dong Sun Lee. This is an open access article distributed under the Creative Commons Attribution License, which permits unrestricted use, distribution, and reproduction in any medium, provided the original work is properly cited.

\begin{abstract}
Two mechanistic microbial growth models (Huang's model and model of Baranyi and Roberts) given in differential and integrated equation forms were compared in predicting the microbial growth and shelf life under dynamic temperature storage and distribution conditions. Literatures consistently reporting the microbial growth data under constant and changing temperature conditions were selected to obtain the primary model parameters, set up the secondary models, and apply them to predict the microbial growth and shelf life under fluctuating temperatures. When evaluated by general estimation behavior, bias factor, accuracy factor, and root-mean-square error, Huang's model was comparable to Baranyi and Roberts' model in the capability to estimate microbial growth under dynamic temperature conditions. Its simple form of single differential equation incorporating directly the growth rate and lag time may work as an advantage to be used in online shelf life estimation by using the electronic device.
\end{abstract}

\section{Introduction}

Microbial growth or spoilage is often the primary quality factor determining the shelf life of many perishable foods [13]. Sometimes it also causes health hazard with pathogenic organisms. Microbial growth model is very useful to decide the shelf life of the packaged perishable foods for any condition of food storage and distribution [2]. Even though the shelf life determination is commonly conducted based on the most probable storage or distribution temperature, temperature abuse or fluctuation occurring in the food supply chain makes it difficult to apply a single shelf life to practical situation $[4,5]$. Dynamic or real-time estimation of the microbial food quality is suggested as a way to ensure the quality level delivered to the consumers and can be realized by devices such as time temperature integrator (TTI) and temperature-monitoring sensor attached on the food packages [6-9]. Recent advances in sensor and communication engineering can handle dynamic storage data for effective shelf life determination of the packaged foods [10-12].
Any dynamic shelf life controls can be possible with appropriate prediction model to estimate the microbial growth under temperature-variant conditions. Several attempts or methods have been reported for this purpose [1315]. Among microbial growth models proposed so far by several researchers, models given in differential equation(s) forms are easier and more powerful to deal with fluctuating temperature conditions [16, 17]. Model of Baranyi and Roberts [18] seems to be the most widely used one for this purpose after its introduction. Recently Huang [19] developed a new mechanistic model to describe the microbial growth in a differential equation form. He also proposed a new functional relationship to express the temperature dependence of growth rate instead of square root model. However, his model has not been tried for predicting microbial growth under dynamic temperature conditions and thus needs to be examined or tested for its capability.

This study therefore aims to apply Huang's mechanistic microbial growth model to dynamic temperature conditions and compare it with model of Baranyi and Roberts in the 
ability to predict the microbial growth of the packaged perishable food in the food supply chain.

\section{Materials and Methods}

2.1. Huang's Model versus Model of Baranyi and Roberts. Huang's model to describe increase rate of cell number $(N)$ against time $(t)$ is written in a differential equation given by [19]

$$
\frac{d N}{d t}=\frac{\mu_{\max }\left(1-N / N_{\max }\right)}{1+\exp [-25(t-\lambda)]}
$$

where $\mu_{\max }, \lambda$, and $N_{\max }$ are maximum specific growth rate, lag time, and maximum cell density, respectively.

Equation (1) can be written in an integrated format of primary model for a constant temperature condition:

$$
\begin{aligned}
& \ln N=\ln N_{o}+ \ln N_{\max } \\
&-\ln \left\{\exp \left(\ln N_{o}\right)+\left[\exp \left(\ln N_{\max }\right)-\exp \left(\ln N_{o}\right)\right]\right. \\
&\left.\cdot \exp \left(-\mu_{\max } B\right)\right\},
\end{aligned}
$$

where $N_{o}$ is initial microbial load and $B=t+(1 / 25) \ln ((1+$ $\exp [-25(t-\lambda)]) /(1+\exp (25 \lambda)))$.

Huang's model needs four parameters of $N_{o}, N_{\max }$, $\mu_{\max }$, and $\lambda$ to characterize a microbial growth curve under constant temperature storage condition.

Model of Baranyi and Roberts [18] is written in two differential equations:

$$
\begin{gathered}
\frac{d q}{d t}=\mu_{\max } q \\
\frac{d N}{d t}=\mu_{\max }\left(\frac{q}{1+q}\right)\left(1-\frac{N}{N_{\max }}\right) N,
\end{gathered}
$$

where $q$ is a hypothetical physiological state of the cell population representing normalized concentration of unknown substance critically needed for cell growth.

Equation (4) in combination with (3) can be formulated into an integrated format of primary model for a constant environmental condition:

$$
\ln N=\ln N_{o}+\mu_{\max } \cdot A-\ln \left(1+\frac{\exp \left(\mu_{\max } A\right)-1}{\exp \left(\ln N_{\max }-\ln N_{\mathrm{o}}\right)}\right),
$$

where $A$ is defined by $A=t+\left(1 / \mu_{\max }\right) \cdot \ln \left[\left(\exp \left(-\mu_{\max } t\right)+\right.\right.$ $\left.\left.q_{o}\right) /\left(1+q_{o}\right)\right]$ and $q_{o}$ is initial state of $q$ at time zero.

Model of Baranyi and Roberts (will be named as Baranyi model later for simplicity) also needs four parameters of $N_{o}$, $N_{\max }, \mu_{\max }$, and $q_{o}$ to characterize a microbial growth curve at constant temperature condition. In their model $\mu_{\max }$ and $q_{o}$ can be related to obtain lag time as

$$
\lambda=\frac{\ln \left(1+1 / q_{o}\right)}{\mu_{\max }} .
$$

While square root model (see (7) and (8)) as secondary model has mostly been used to describe the temperature dependence of growth rate and lag time in many predictive models including that of Baranyi and Roberts [13, 20], Huang [19] proposed using a different form of (9) for growth rate. Consider the following:

$$
\begin{gathered}
\sqrt{\mu_{\max }}=a\left(T-T_{\min }\right), \\
\sqrt{\frac{1}{\lambda}}=a\left(T-T_{\min }\right), \\
\mu_{\max }=a\left(T-T_{\min }\right)^{1.5},
\end{gathered}
$$

where $a$ and $T_{\min }$ are constant and minimum growth temperature for each equation, respectively.

2.2. Literature Data for Testing. Usually in dynamic shelf life modeling, it is assumed that kinetic parameters are obtained from growth experiments at constant temperatures and their temperature dependence is established to be applied to temperature-variant conditions. All those functional relationships should be verified in temperature-changing storage and distribution of food packages. Thus literatures reporting microbial growth data sufficiently under constant and fluctuating temperature conditions in consistent way were looked for to test and compare the two models of microbial growth. Growth data of pseudomonads on seabream from Koutsoumanis [21], those of Escherichia coli O157:H7 and Salmonella spp. on lettuce from Koseki and Isobe [22], and of lactic acid bacterial growth data on cured meat from Mataragas et al. [16] were collected and used in this study. Even though pathogenic bacteria such as E. coli and Salmonella are not usually used for shelf life determination, the data from Koseki and Isobe [22] were included for the analysis in this study due to their consistency and relevance in relation to product supply chain to the consumers. Primary model parameters under constant temperature conditions were obtained by nonlinear regression of the data in (2) and (5) except that those given by Koseki and Isobe [22] were directly adopted for the Baranyi model. Secondary model parameters for (7), (8), and (9) were also determined by linear or nonlinear regression.

\section{Results and Discussion}

3.1. Adequacy Evaluation of the Simulation Models Using Literature Data. Table 1 shows parameters of primary model, for both Huang and Baranyi models, which were determined or taken for the literature sources. From the primary model parameters, secondary models to express the functional relationship of temperature effect on microbial growth have been presented in the literature or can be formulated following (7), (8), and/or (9). Summarized results are given in Table 2, and those relationships could be connected to the solution of differential equation (1) for Huang model and to that of (3) and (4) for Baranyi model. Maximum cell density $\left(N_{\max }\right)$ is assumed to be indifferent to temperature or be in a simple linear function of temperature depending on the 
TABLE 1: Parameters of the primary models for the microbial growth data under constant temperature conditions.

\begin{tabular}{|c|c|c|c|c|c|c|c|c|}
\hline \multirow{2}{*}{ Microorganism } & \multirow{2}{*}{ Temperature $\left({ }^{\circ} \mathrm{C}\right)$} & \multicolumn{3}{|c|}{ Huang } & \multicolumn{3}{|c|}{ Baranyi } & \multirow{2}{*}{ Source of data } \\
\hline & & $\lambda(\mathrm{d})$ & $\mu_{\max }\left(\mathrm{d}^{-1}\right)$ & $\ln N_{\max }$ & $\lambda(\mathrm{d})$ & $\mu_{\max }\left(\mathrm{d}^{-1}\right)$ & $\ln N_{\max }$ & \\
\hline \multirow{6}{*}{ Pseudomonads } & 0 & 1.38 & 1.21 & 20.3 & 1.62 & 1.25 & 20.2 & \multirow{6}{*}{ Koutsoumanis [21] } \\
\hline & 2 & 1.07 & 1.50 & 18.5 & 1.12 & 1.55 & 18.5 & \\
\hline & 5 & 0.28 & 2.27 & 19.0 & 0.30 & 2.31 & 18.9 & \\
\hline & 8 & 0.35 & 3.53 & 18.6 & 0.34 & 3.40 & 18.6 & \\
\hline & 10 & 0.45 & 4.17 & 18.5 & 0.46 & 4.38 & 18.4 & \\
\hline & 15 & 0.21 & 6.50 & 18.6 & 0.21 & 6.68 & 18.6 & \\
\hline \multirow{4}{*}{ E. coli $\mathrm{O} 157: \mathrm{H7}$} & 10 & 1.42 & 2.08 & 13.6 & 1.36 & 1.66 & 11.6 & \multirow{4}{*}{ Koseki and Isobe [22] } \\
\hline & 15 & 0.34 & 8.02 & 14.5 & 0.31 & 6.63 & 13.9 & \\
\hline & 20 & 0.23 & 19.61 & 14.6 & 0.22 & 14.37 & 14.6 & \\
\hline & 25 & 0.14 & 25.00 & 15.6 & 0.19 & 24.32 & 15.7 & \\
\hline \multirow{4}{*}{ Salmonella spp. } & 10 & 1.65 & 1.88 & 11.6 & 1.46 & 1.11 & 11.6 & \multirow{4}{*}{ Koseki and Isobe [22] } \\
\hline & 15 & 0.28 & 8.63 & 12.6 & 0.27 & 7.19 & 12.4 & \\
\hline & 20 & 0.23 & 16.84 & 14.0 & 0.22 & 14.37 & 13.8 & \\
\hline & 25 & 0.15 & 32.89 & 14.6 & 0.12 & 22.66 & 15.0 & \\
\hline \multirow{4}{*}{ Lactic acid bacteria } & 0 & 2.83 & 0.32 & 19.5 & 1.89 & 0.32 & 19.5 & \multirow{4}{*}{ Mataragas et al. [16] } \\
\hline & 4 & 1.40 & 0.58 & 19.8 & 0.76 & 0.57 & 19.8 & \\
\hline & 8 & 1.41 & 1.33 & 18.4 & 1.52 & 1.36 & 18.4 & \\
\hline & 12 & 0.30 & 1.86 & 20.0 & 0.17 & 1.73 & 20.0 & \\
\hline
\end{tabular}

TABLE 2: Secondary models used for the microbial growth estimation.

\begin{tabular}{|c|c|c|c|c|}
\hline Microorganism & Parameter & Huang & Baranyi & Source of data \\
\hline Pseudomonads & $\begin{array}{c}\lambda(\mathrm{d}) \text { or } q_{o} \\
\mu_{\max }\left(\mathrm{d}^{-1}\right) \\
\ln N_{\max }\end{array}$ & $\begin{array}{c}\lambda=95.51 /\{T-(-8.22)\}^{2} \\
\mu_{\max }=0.067\{T-(-5.94)\}^{1.5} \\
\ln N_{\max }=18.91\end{array}$ & $\begin{array}{c}q_{o}=0.38 \\
\mu_{\max }=[0.010\{T-(-10.63)\}]^{2} \\
\ln N_{\max }=18.89\end{array}$ & Koutsoumanis [21] \\
\hline E. coli $\mathrm{O} 157: \mathrm{H7}$ & $\begin{array}{c}\lambda(\mathrm{d}) \text { or } q_{o} \\
\mu_{\max }\left(\mathrm{d}^{-1}\right) \\
\ln N_{\max }\end{array}$ & $\begin{array}{c}\lambda=72.80 /(T-1.91)^{2} \\
\mu_{\max }=0.170(T-0.74)^{1.5} \\
\ln N_{\max }=0.118 T+12.51\end{array}$ & $\begin{array}{c}q_{o}=0.06 \\
\mu_{\max }=\{0.060(T-4.54)\}^{2} \\
\ln N_{\max }=0.218 T+10.32\end{array}$ & Koseki and Isobe [22] \\
\hline Salmonella spp. & $\begin{array}{c}\lambda(\mathrm{d}) \text { or } q_{o} \\
\mu_{\max }\left(\mathrm{d}^{-1}\right) \\
\ln N_{\max }\end{array}$ & $\begin{array}{c}\lambda=78.87 /(T-1.23)^{2} \\
\mu_{\max }=0.266(T-4.89)^{1.5} \\
\ln N_{\max }=0.206 T+9.62\end{array}$ & $\begin{array}{c}q_{o}=0.11 \\
\mu_{\max }=\{0.060(T-4.96)\}^{2} \\
\ln N_{\max }=0.257 T+8.64\end{array}$ & Koseki and Isobe [22] \\
\hline Lactic acid bacteria & $\begin{array}{l}\lambda(\mathrm{d}) \text { or } q_{o} \\
\mu_{\max }\left(\mathrm{d}^{-1}\right) \\
\ln N_{\max }\end{array}$ & $\begin{array}{c}\lambda=117.4 /\{T-(-5.13)\}^{2} \\
\mu_{\max }=0.028\{T-(-4.41)\}^{1.5} \\
\ln N_{\max }=19.43\end{array}$ & $\begin{array}{c}q_{o}=1.54 \\
\mu_{\max }=[0.066\{T-(-8.36)\}]^{2} \\
\ln N_{\max }=19.44\end{array}$ & Mataragas et al. [16] \\
\hline
\end{tabular}

microbial strains (Table 2). For the Baranyi model using (3), $q$ at initial state $\left(q_{o}\right)$ is required, and average values from constant temperature conditions have been used as in many other studies $[13,23]$ and thus are given in Table 2.

Figures 1-4 show the results of microbial growth estimation for pseudomonads, E. coli O157:H7, Salmonella, and lactic acid bacteria under dynamic temperature conditions. All the estimated microbial evolutions through time generally agreed with those worked by the respective researchers $[16$, $21,22]$. Huang model gave predictions pretty close to the experimental data of pseudomonads on fish and almost identical to those given by Baranyi model (Figure 1). Only slight discrepancy from the experimental data happened after passing lag time before reaching the stationary phase in Figure 1(b) in the same way with Baranyi model. In predicting
E. coli growth on the lettuce under dynamic temperature conditions, Huang model seems to be better than Baranyi model in the estimation except for the last duration of storage (Figure 2). Prediction of higher count than experimental data may be due to the slight decrease of the microbial load in the extended storage of the lettuce, which is not common in usual food storage and is rarely accounted for in most microbial growth modeling. The outcome of the higher prediction is thought to be a kind of fail-safe phenomenon. The similar trend was observed for the estimation of Salmonella growth (Figure 3). Both models were poor with prediction of higher Salmonella growth than the real data under dynamic temperature conditions of Figure 3(b). Almost same degree of estimations was observed between two models for lactic acid bacteria growth under two nonisothermal conditions 


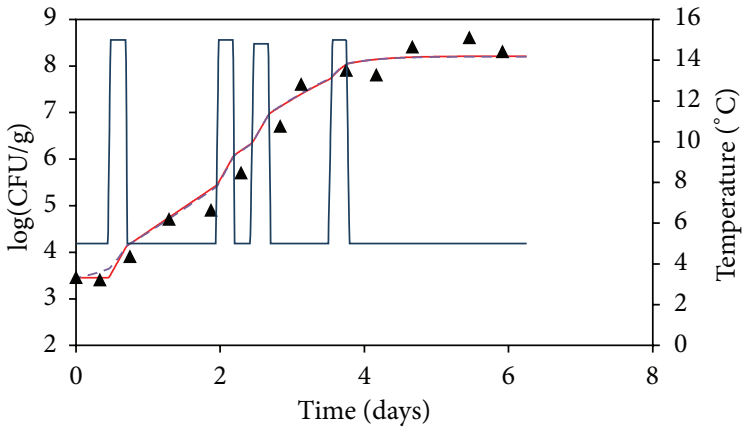

(a)

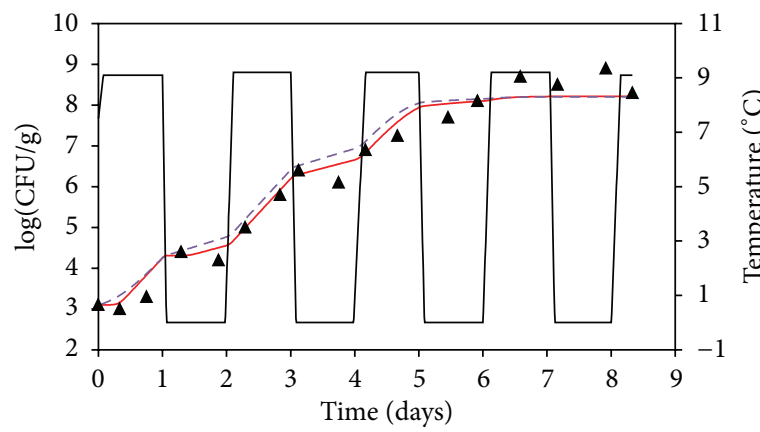

(c)

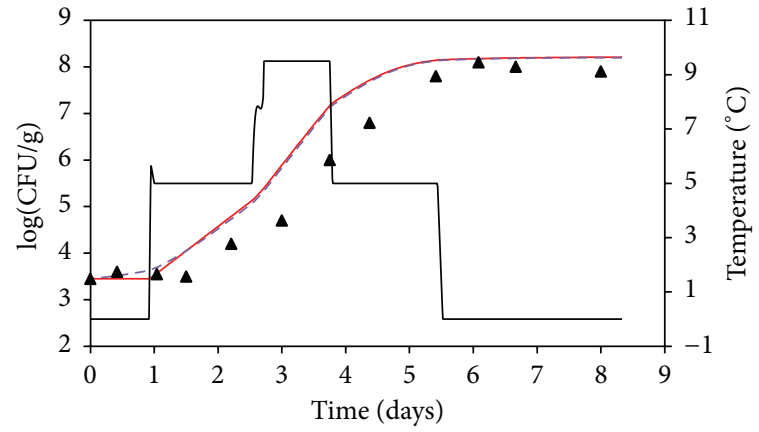

(b)

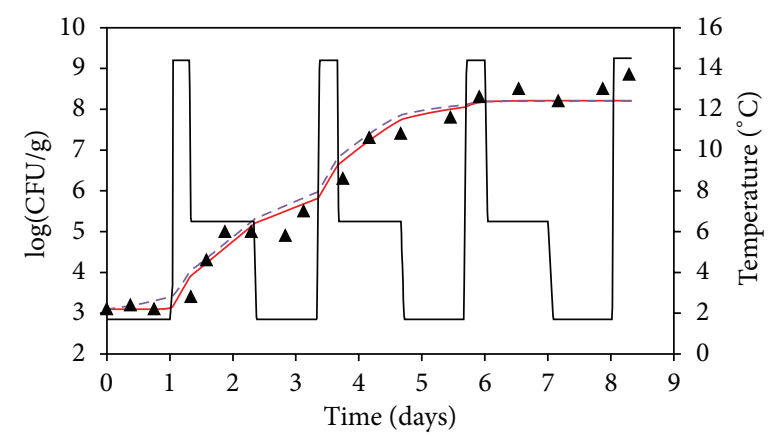

(d)

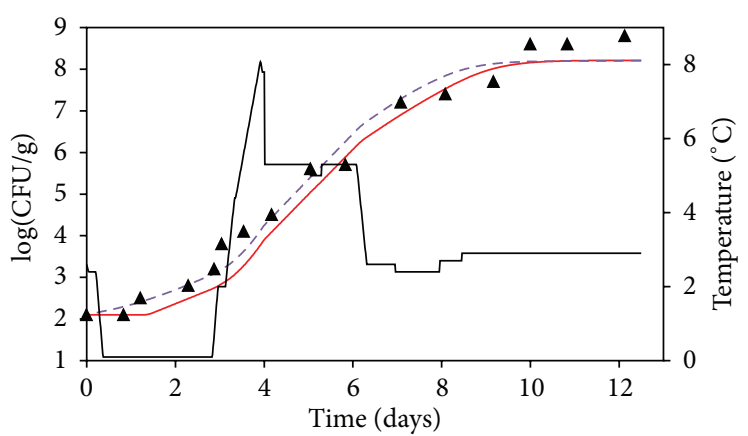

(e)

FIGURE 1: Estimation of pseudomonads growth under several fluctuating temperature conditions. Experimental data are from Koutsoumanis [21]. Thin solid lines are the temperature, and thick solid and dotted lines are microbial counts estimated by Huang and Barayi models, respectively. $\mathbf{\Lambda}$ : experimental microbial count.

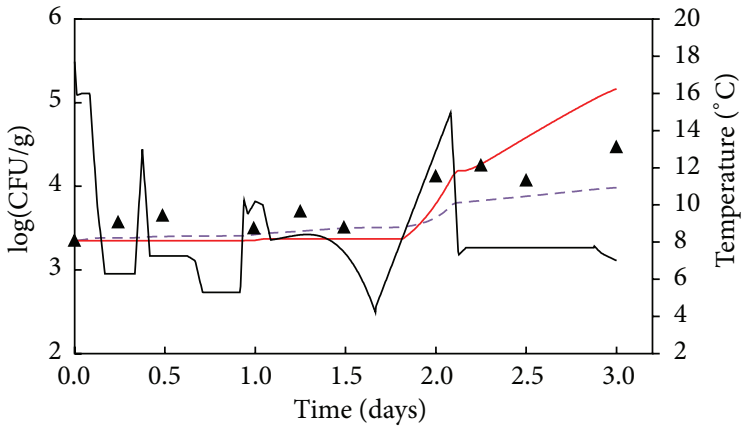

(a)

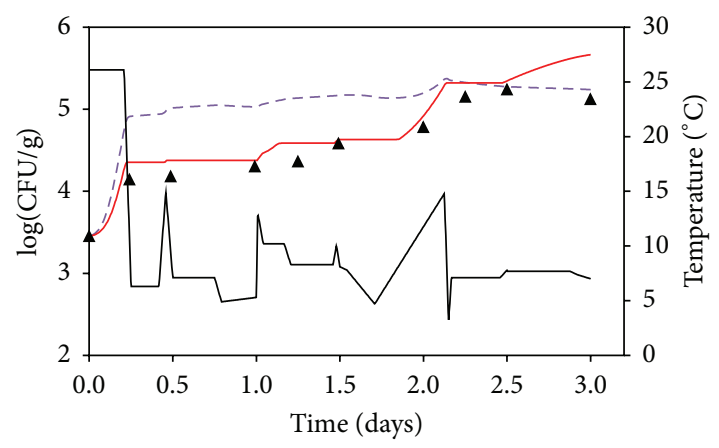

(b)

Figure 2: Estimation of E. coli O157:H7 growth under two fluctuating temperature conditions. Experimental data are from Koseki and Isobe [22]. Thin solid lines are the temperature, and thick solid and dotted lines are microbial counts estimated by Huang and Barayi models, respectively. $\mathbf{\Delta}$ : experimental microbial count. 


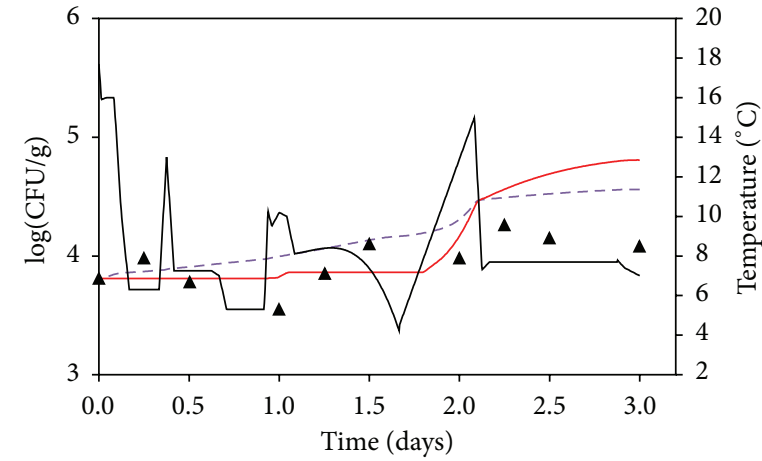

(a)

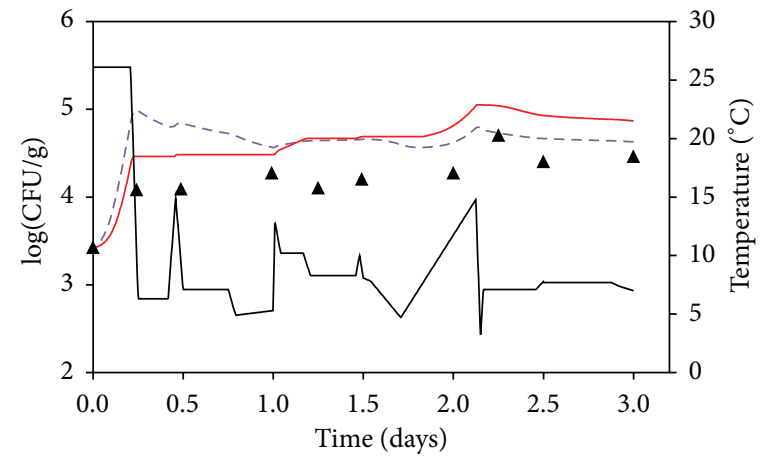

(b)

FIGURE 3: Estimation of Salmonella growth under two fluctuating temperature conditions. Experimental data are from Koseki and Isobe [22]. Thin solid lines are the temperature, and thick solid and dotted lines are microbial counts estimated by Huang and Barayi models, respectively. $\Delta$ : experimental microbial count.

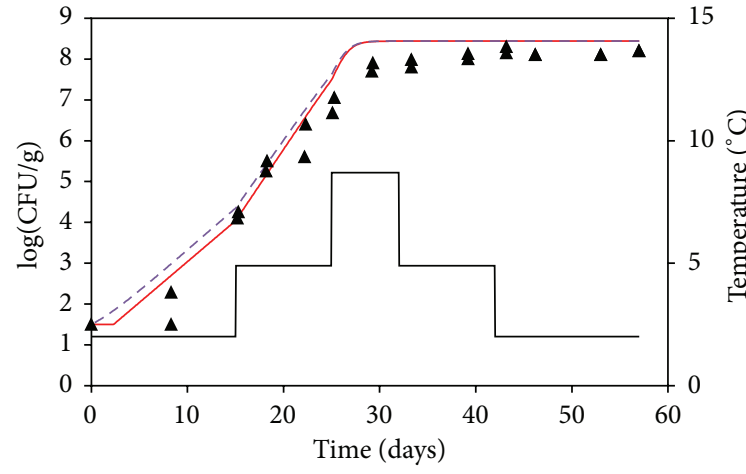

(a)

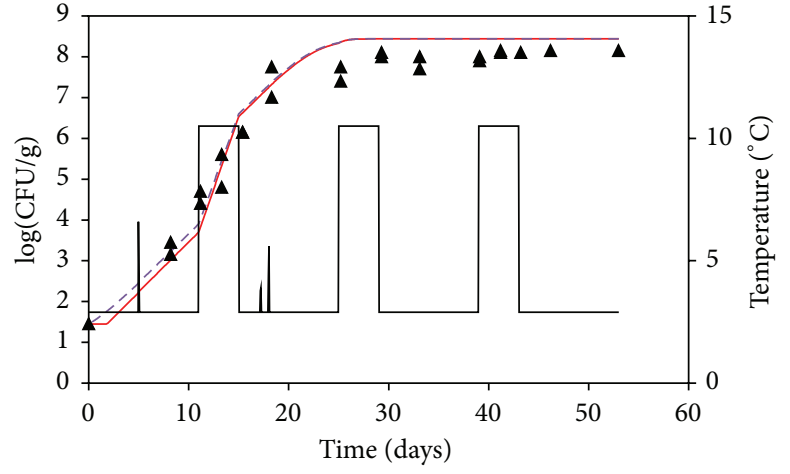

(b)

Figure 4: Estimation of lactic acid bacteria growth under two fluctuating temperature conditions. Experimental data are from Mataragas et al. [16]. Thin solid lines are the temperature, and thick solid and dotted lines are microbial counts estimated by Huang and Barayi models, respectively. $\mathbf{\Delta}$ : experimental microbial count.

(Figure 4). A slight but clear difference between two models is that Huang model shows more distinct ending of lag time for all the conditions.

Table 3 summarizes the comparison between two models in terms of the prediction parameters of bias factor $(\mathrm{BF})$, accuracy factor (AF), and root-mean-square error (RMSE), which were defined as follows:

$$
\begin{gathered}
\mathrm{BF}=\exp \left(\frac{\sum \ln \left(\log _{10} N_{p} / \log _{10} N_{o}\right)}{n}\right), \\
\mathrm{AF}=\exp \left(\frac{\sum\left|\ln \left(\log _{10} N_{p} / \log _{10} N_{o}\right)\right|}{n}\right), \\
\mathrm{RMSE}=\sqrt{\frac{\sum\left(\log _{10} N_{p}-\log _{10} N_{o}\right)^{2}}{n}},
\end{gathered}
$$

where $N_{p}$ is the predicted microbial count (CFU/g), $N_{o}$ is the experimental count (CFU/g), and $n$ is number of data.
Overall in terms of the prediction parameters, Huang and Baranyi models showed a similar degree of prediction capacity in predicting the microbial growth under fluctuating temperature conditions (Table 3). For the used literature data sets, BF for Haung model ranged from 0.92 to 1.08 and that for Baranyi model was from 0.93 to 1.11. AF was from 1.04 to 1.18 for Haung model and from 1.04 to 1.11 for Baranyi model. RMSE was from 0.24 to 0.86 for Haung model and from 0.17 to 0.61 for Baranyi model. These ranges of $\mathrm{BF}$ and $\mathrm{AF}$ are considered adequate or acceptable $[16,23]$. BF and AF values from both models in pseudomonads were closer to 1.0 than those obtained originally by Koutsoumanis [21] using fourparameter logistic primary model and square root secondary model. This is a verification showing the advantage of these two mechanistic models over the latter model. $\mathrm{BF}$ and $\mathrm{AF}$ values of Baranyi analysis for lactic acid bacteria on cured meat in Table 3 are close to those obtained by Mataragas et al. [16].

As a way to validate the microbial growth models, time to reach an acceptable limit of microbial load $\left(10^{7}\right.$ cells/g for pseudomonads and $10^{8.4}$ cells/g for lactic acid bacteria) was 
TABLE 3: Evaluation of the prediction of microbial growth under dynamic temperature conditions.

\begin{tabular}{|c|c|c|c|c|c|c|}
\hline \multirow{2}{*}{ Conditions and microorganism } & \multicolumn{2}{|c|}{$\mathrm{BF}$} & \multicolumn{2}{|c|}{$\mathrm{AF}$} & \multicolumn{2}{|c|}{ RMSE $\left(\log _{10}\right.$ CFU/g) } \\
\hline & Huang & Baranyi & Huang & Baranyi & Huang & Baranyi \\
\hline Pseudomonads in Figure 1(a) & 1.037 & 1.039 & 1.056 & 1.058 & 0.511 & 0.515 \\
\hline Pseudomonads in Figure 1(b) & 1.081 & 1.083 & 1.089 & 1.087 & 0.633 & 0.607 \\
\hline Pseudomonads in Figure 1(c) & 1.013 & 1.038 & 1.044 & 1.062 & 0.324 & 0.416 \\
\hline Pseudomonads in Figure 1(d) & 1.009 & 1.027 & 1.045 & 1.056 & 0.325 & 0.387 \\
\hline Pseudomonads in Figure 1(e) & 0.918 & 0.982 & 1.102 & 1.062 & 0.480 & 0.373 \\
\hline E. coli $\mathrm{O} 157: \mathrm{H} 7$ in Figure $2(\mathrm{a})$ & 0.984 & 0.967 & 1.078 & 1.042 & 0.356 & 0.182 \\
\hline E. coli $\mathrm{O} 157: \mathrm{H7}$ in Figure 2(b) & 1.041 & 1.110 & 1.041 & 1.110 & 0.236 & 0.577 \\
\hline Salmonella spp. in Figure 3(a) & 1.044 & 1.059 & 1.068 & 1.066 & 0.351 & 0.299 \\
\hline Salmonella spp. in Figure 3(b) & 0.998 & 1.099 & 1.181 & 1.099 & 0.858 & 0.496 \\
\hline Lactic acid bacteria in Figure 4(a) & 1.073 & 1.097 & 1.082 & 1.098 & 0.506 & 0.585 \\
\hline Lactic acid bacteria in Figure 4(b) & 1.018 & 1.033 & 1.075 & 1.068 & 0.496 & 0.480 \\
\hline
\end{tabular}

TABLE 4: Shelf life prediction by Huang and Baranyi models.

\begin{tabular}{lcccc}
\hline $\begin{array}{l}\text { Spoilage organism and } \\
\text { temperature condition }\end{array}$ & $\begin{array}{c}\text { Shelf life predicted (days) } \\
\text { Huang }\end{array}$ & Baranyi & $\begin{array}{c}\text { Shelf life predicted } \\
\text { in the source (days) }\end{array}$ & $\begin{array}{c}\text { Criterion of spoilage } \\
\text { level at end of shelf life }\end{array}$ \\
\hline Pseudomonads in Figure 1(a) & 2.7 & 2.7 & 3.0 & $10^{7} / \mathrm{g}$ \\
Pseudomonads in Figure 1(b) & 3.6 & 3.7 & 3.8 & $10^{7} / \mathrm{g}$ \\
Pseudomonads in Figure 1(c) & 4.3 & 4.1 & 4.2 & $10^{7} / \mathrm{g}$ \\
Pseudomonads in Figure 1(d) & 4.0 & 3.8 & 6.9 & $10^{7} / \mathrm{g}$ \\
Pseudomonads in Figure 1(e) & 7.2 & 6.7 & 28 & $10^{7} / \mathrm{g}$ \\
Lactic acid bacteria in Figure 4(a) & 28.3 & 28.2 & 24 & $10^{8.4} / \mathrm{g}$ \\
Lactic acid bacteria in Figure 4(b) & 25.7 & 25.6 & $10^{8.4} / \mathrm{g}$ \\
\hline
\end{tabular}

calculated as shelf life estimate. The shelf life estimates based on the criteria set in the literatures were almost the same between Huang and Baranyi models and also similar to the predicted values given in the sources (Table 4).

Huang model has advantage of directly determining the growth rate and lag time from the fitting of its primary model to the microbial growth data at constant temperature, which can also be used for building secondary model. Relationships of growth rate and lag time as function of temperature may affect the model's capability to predict the microbial growth under nonisothermal conditions. Huang [19] proposed (9) for growth rate and (8) for the lag time. Because it is difficult to predict lag phase duration and express its temperature dependence in simple square root model [24], there may still remain a possible limitation in Huang model's capability to predict the microbial growth under varying temperature conditions. Baranyi model has been set up based on theoretical hypothesis of microbial growth and usually needs only (7) for secondary model defining the temperature dependence of the growth rate $[13,16,22]$. However, selection of proper $q_{o}$ value or initial physiological cell state is known to be critical for successful estimation of microbial growth under dynamic temperature conditions by using two simultaneous differential equations (3) and (4) $[13,22]$. Even though $q_{o}$ values from different temperature are averaged for use in fluctuating temperature storage, too much different values from several temperature conditions make it difficult to determine the proper value $[7,19]$. From the finding that Huang model is comparable to Baranyi model in estimating the microbial growth under dynamic temperature conditions, its simplicity in using single differential equation (1) with direct incorporation of the growth rate and lag time may work as an advantage for application of plugging into quality estimation devices such as RFID or other electronic sensors, which are being introduced recently for the shelf life control $[10,11]$.

Even with some limitations, Huang and Baranyi models are found to work effectively to predict the microbial growth dynamics under changing temperature conditions being useful for shelf life estimation and control in dynamic food supply chain.

\section{Conclusions}

Huang model was comparable to Baranyi model in the capability to estimate microbial growth under dynamic temperature conditions. Its simple form of single differential equation incorporating directly the growth rate and lag time may work as an advantage to be used in online shelf life estimation by using the electronic device.

\section{Conflict of Interests}

The author declares that there is no conflict of interests regarding the publication of this paper. 


\section{Acknowledgments}

This work was supported by Kyungnam University Foundation Grant, 2013. The author thanks Yun Hee Jo, Min-Ji Kwon, and Ji Hye Lee for reading the data from the literatures.

\section{References}

[1] T. A. McMeekin and T. Ross, "Shelf life prediction: status and future possibilities," International Journal of Food Microbiology, vol. 33, no. 1, pp. 65-83, 1996.

[2] K. Koutsoumanis and G.-J. E. Nychas, "Application of a systematic experimental procedure to develop a microbial model for rapid fish shelf life predictions," International Journal of Food Microbiology, vol. 60, no. 2-3, pp. 171-184, 2000.

[3] D. S. Lee, "Packaging and the microbial shelf life of food," in Food Packaging and Shelf Life, G. L. Robertson, Ed., pp. 55-79, CRC Press, Boca Raton, Fla, USA, 2009.

[4] T. Tsironi, E. Gogou, E. Velliou, and P. S. Taoukis, "Application and validation of the TTI based chill chain management system SMAS (Safety Monitoring and Assurance System) on shelf life optimization of vacuum packed chilled tuna," International Journal of Food Microbiology, vol. 128, no. 1, pp. 108-115, 2008.

[5] S. Bruckner, B. Petersen, and J. Kreyenschmidt, "Influence of cold chain interruptions on the shelf life of fresh pork and poultry," International Journal of Food Science and Technology, vol. 47, no. 8, pp. 1639-1646, 2012.

[6] P. S. Taoukis, K. Koutsoumanis, and G. J. E. Nychas, "Use of time-temperature integrators and predictive modelling for shelf life control of chilled fish under dynamic storage conditions," International Journal of Food Microbiology, vol. 53, no. 1, pp. 2131, 1999.

[7] D. S. Lee, K.-J. Hwang, D. S. An, J. P. Park, and H. J. Lee, "Model on the microbial quality change of seasoned soybean sprouts for on-line shelf life prediction," International Journal of Food Microbiology, vol. 118, no. 3, pp. 285-293, 2007.

[8] I. Seo, D. S. An, and D. S. Lee, "Development of convenient software for online shelf-life decisions for Korean prepared side dishes based on microbial spoilage," Food Science and Biotechnology, vol. 18, no. 5, pp. 1243-1252, 2009.

[9] J. K. Heising, M. Dekker, P. V. Bartels, and M. A. J. S. (Tiny) Van Boekel, "Monitoring the quality of perishable foods: opportunities for intelligent packaging," Critical Reviews in Food Science and Nutrition, vol. 54, no. 5, pp. 645-654, 2014.

[10] L. Qi, M. Xu, Z. Fu, T. Mira, and X. Zhang, "C ${ }^{2}$ SLDS: a WSNbased perishable food shelf-life prediction and LSFO strategy decision support system in cold chain logistics," Food Control, vol. 38, no. 1, pp. 19-29, 2014.

[11] M. Kärkkäinen, "Increasing efficiency in the supply chain for short shelf life goods using RFID tagging," International Journal of Retail \& Distribution Management, vol. 31, no. 10, pp. 529-536, 2003.

[12] K. L. Yam, P. T. Takhistov, and J. Miltz, "Intelligent packaging: concepts and applications," Journal of Food Science, vol. 70, no. 1, pp. R1-R10, 2005.

[13] J. Baranyi, T. P. Robinson, A. Kaloti, and B. M. Mackey, "Predicting growth of Brochothrix thermosphacta at changing temperature," International Journal of Food Microbiology, vol. 27, no. 1, pp. 61-75, 1995.

[14] L. Huang, "Estimation of growth of Clostridium perfringens in cooked beef under fluctuating temperature conditions," Food Microbiology, vol. 20, no. 5, pp. 549-559, 2003.
[15] K. Koutsoumanis, P. S. Taoukis, and G. J. E. Nychas, “Development of a safety monitoring and assurance system for chilled food products," International Journal of Food Microbiology, vol. 100, no. 1-3, pp. 253-260, 2005.

[16] M. Mataragas, E. H. Drosinos, A. Vaidanis, and I. Metaxopoulos, "Development of a predictive model for spoilage of cooked cured meat products and its validation under constant and dynamic temperature storage conditions," Journal of Food Science, vol. 71, no. 6, pp. M157-M167, 2006.

[17] J. F. van Impe, F. Poschet, A. H. Geeraerd, and K. M. Vereecken, "Towards a novel class of predictive microbial growth models," International Journal of Food Microbiology, vol. 100, no. 1-3, pp. 97-105, 2005.

[18] J. Baranyi, "Mathematics of predictive food microbiology," International Journal of Food Microbiology, vol. 26, no. 2, pp. 199-218, 1995.

[19] L. Huang, "A new mechanistic growth model for simultaneous determination of lag phase duration and exponential growth rate and a new Bělehdrádek-type model for evaluating the effect of temperature on growth rate," Food Microbiology, vol. 28, no. 4, pp. 770-776, 2011.

[20] K. Bernaerts, E. Dens, K. Vereecken et al., "Modeling microbial dynamics under time-varying conditions," in Modeling Microbial Responses in Food, R. C. McKellar and X. Lu, Eds., pp. 243261, CRC Press, Boca Raton, Fla, USA, 2004.

[21] K. Koutsoumanis, "Predictive modeling of the shelf life of fish under nonisothermal conditions," Applied and Environmental Microbiology, vol. 67, no. 4, pp. 1821-1829, 2001.

[22] S. Koseki and S. Isobe, "Prediction of pathogen growth on iceberg lettuce under real temperature history during distribution from farm to table," International Journal of Food Microbiology, vol. 104, no. 3, pp. 239-248, 2005.

[23] D. A. Longhi, F. Dalcanton, G. M. de Aragão, B. A. Carciofi, and J. B. Laurindo, "Assessing the prediction ability of different mathematical models for the growth of Lactobacillus plantarum under non-isothermal conditions," Journal of Theoretical Biology, vol. 335, no. 1, pp. 88-96, 2013.

[24] I. A. M. Swinnen, K. Bernaerts, E. J. J. Dens, A. H. Geeraerd, and J. F. van Impe, "Predictive modelling of the microbial lag phase: a review," International Journal of Food Microbiology, vol. 94, no. 2, pp. 137-159, 2004. 


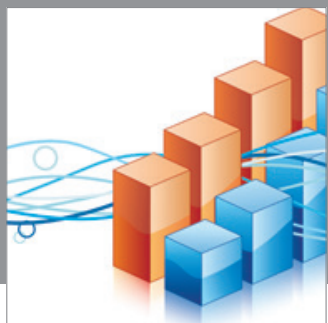

Advances in

Operations Research

mansans

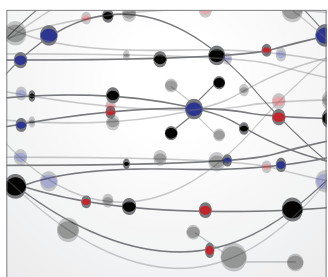

The Scientific World Journal
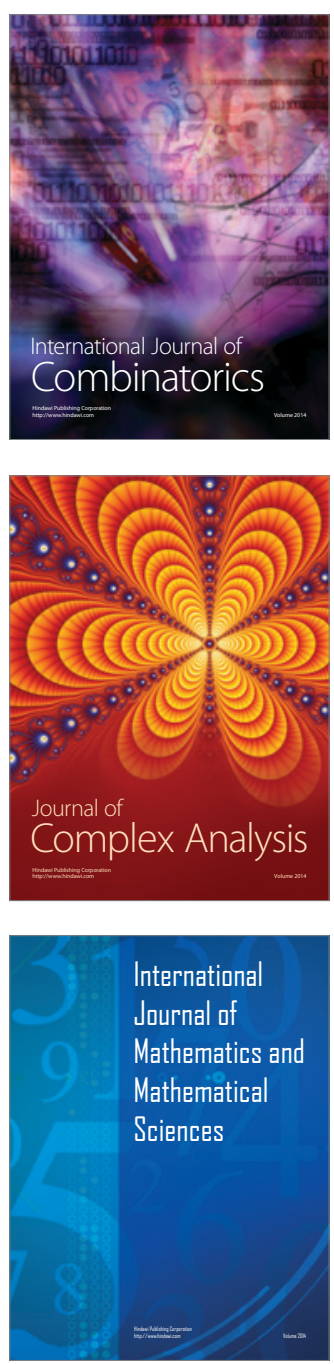
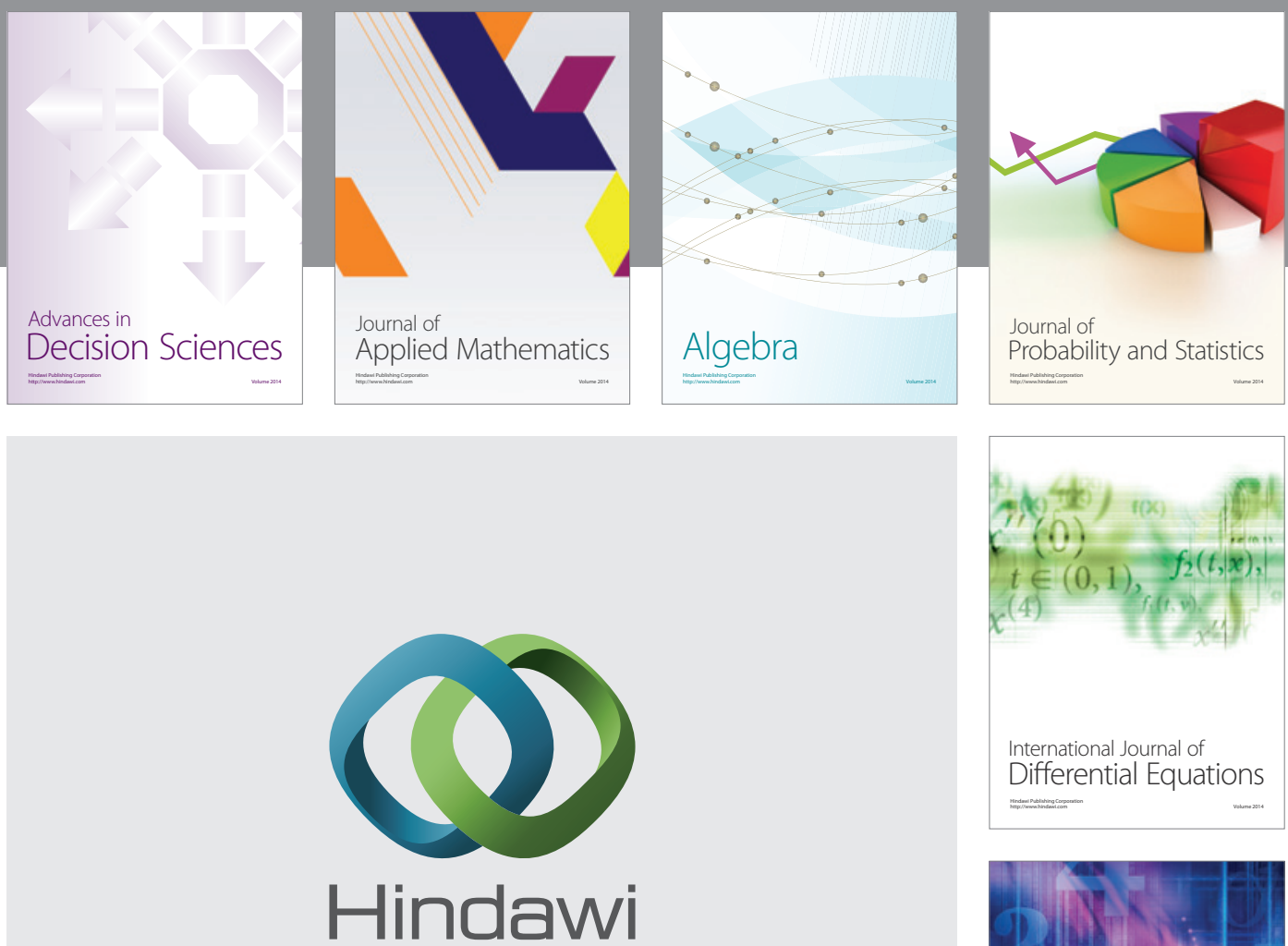

Submit your manuscripts at http://www.hindawi.com
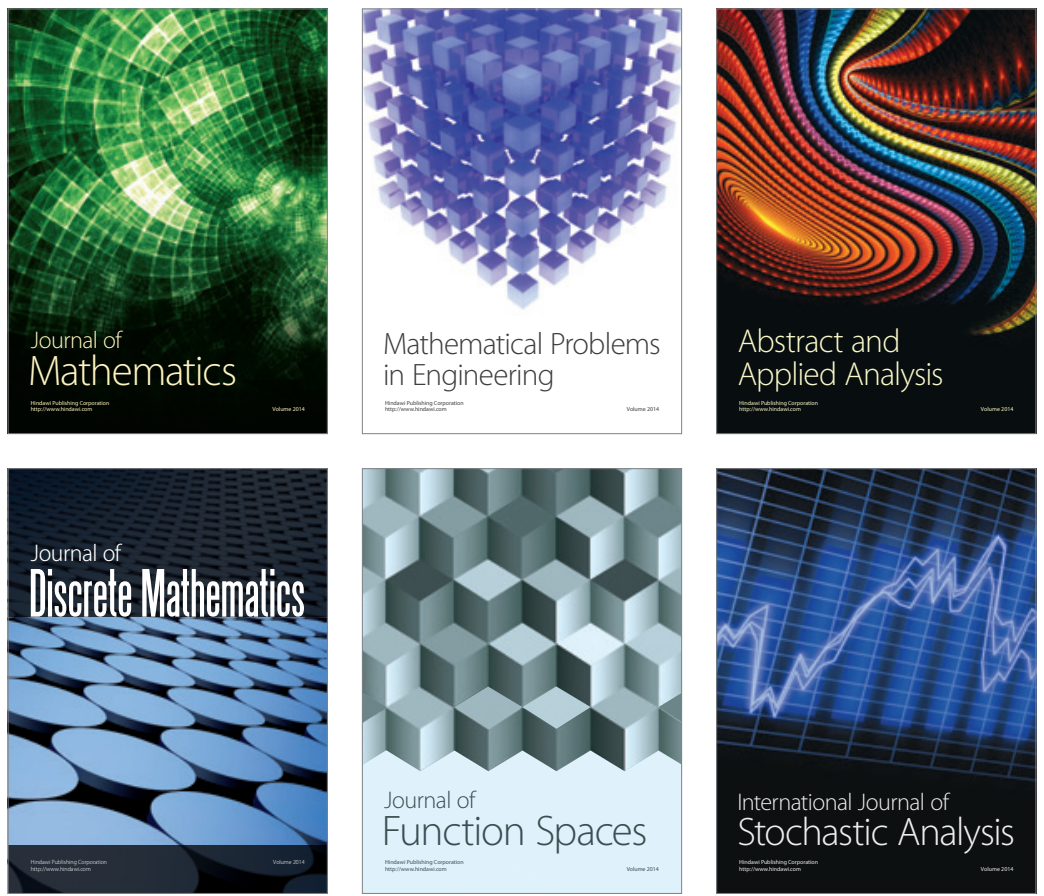

Journal of

Function Spaces

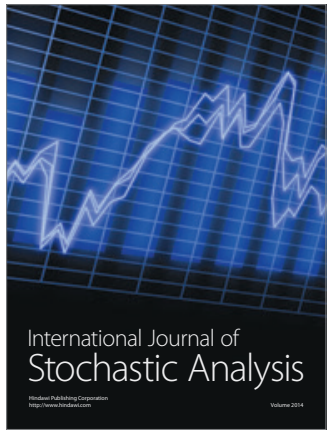

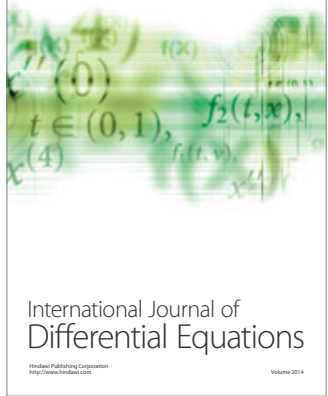
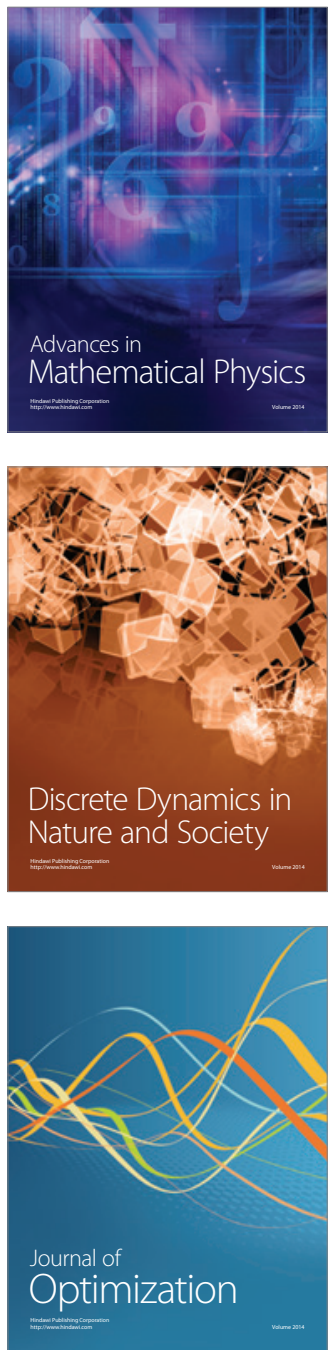